\title{
LITERATURA PARA A ESCOLA PRIMÁRIA E EDUCAÇÃO DO CIDADÃO REPUBLICANO, NA REVISTA DE ENSINO (SP-BRASIL) - 1902/1918
}

DOI: http://dx.doi.org/10.1590/2236-3459/75780

\author{
Maria do Rosário Longo Mortattil \\ 'Universidade Estadual Paulista (Unesp), Marília/SP, Brasil
}

$\cos$

\begin{abstract}
Resumo
Visando a contribuir para compreender aspectos inexplorados da história da literatura infantil, do ensino de leitura e escrita e da educação no Brasil, enfoca-se a Seção "Literatura infantil" da Revista de Ensino, editada entre 1902 e 1918, pela Associação Beneficente do Professorado Público Paulista. Por meio da análise da configuração dos textos publicados na Seção, constata-se que as traduções/adaptações, paráfrases ou textos originais de autores brasileiros ou estrangeiros integram o corpus precursor da literatura infantil brasileira, tendo contribuído para disseminar a concepção de literatura infantil oscilante entre gênero didático e gênero literário, articuladamente à função da escola primária, no projeto republicano de modernização social e cultural necessária à construção da nação.

Palavras-chave: literatura infantil, Revista de Ensino, história da literatura infantil, história do ensino de leitura e escrita, história da educação no Brasil.

\section{LITERATURA PARA LA ESCUELA PRIMARIA Y EDUCACIÓN DEL CIUDADANO REPUBLICANO, EN LA REVISTA DE ENSINO (SP-BRAZIL) - 1902/1918}

\section{Resumen}

Con el objetivo de contribuir a comprender aspectos de la historia de la literatura infantil, de la enseñanza de lectura y escritura y de la educación en Brasil, se enfoca la Sección "Literatura infantil" de la Revista de Ensino, editada de 1902 a 1918, por la Asociación Beneficente del Profesorado Público Paulista. Por medio del análisis de la configuración de los textos allí publicados, se constata que las traducciones/adaptaciones, párrafos o textos originales de autores brasileños o extranjeros integran el corpus precursor de la literatura infantil brasileña y contribuyeron a diseminar la concepción oscilante entre género didáctico y literario, articulada a la función de la escuela primaria en el proyecto republicano de modernización social y cultural para la construcción de la nación.

Palabras clave: literatura infantil, Revista de Ensino, historia de la literatura infantil, historia de la enseñanza de lectura y escritura, historia de la educación en Brasil.

\footnotetext{
1 Tradução do original em inglês (MORTATTI, 2015), publicado na revista History of Education \& Children's Literature. Este texto resulta de pesquisa concluída pela autora em 1993, vinculada ao Grupo de Pesquisa "História da educação e do ensino de língua e literatura no Brasil" - GPHEELLB, criado em 1994 e atualmente sediado na Unesp - campus de Marília/SP, Brasil.
} 


\title{
LITERATURE FOR PRIMARY SCHOOL AND EDUCATION OF REPUBLICAN CITIZEN, IN THE REVISTA DE ENSINO (SP-BRAZIL) - 1902-1918
}

\begin{abstract}
Aiming to contribute to understand unexplored aspects of the history of children's literature, of teaching reading and of education in Brazil, is focused the Section "Children's Literature" of the Revista de Ensino, edited between 1902 and 1918, by Beneficent Association of Public Teachers of Sao Paulo State. By means of analyzing the configuration of the texts published in this Section, it is concluded that: the translations/adaptations, paraphrases or original texts by Brazilian or foreign authors characterizes a precursor corpus of the Brazilian children's literature and contributed to disseminate a conception of children's literature that oscillates between didactic and literary genre, articulated with the purposes of primary school education under a republican project to the nation.

Keywords: children's literature, Revista de Ensino, history of children's literature, history of teaching reading, history of education in Brazil.

\section{LITTÉRATURE POUR L'ÉCOLE PRIMAIRE ET L'ÉDUCATION DU CITOYEN RÉPUBLICAIN, DANS LE REVISTA DE ENSINO (SP-BRÉSIL) - 1902/1918}

\section{Résumé}

Afin de contribuer à la compréhension des aspects inexplorés de l'histoire de la littérature enfantine, l'enseignement de la lecture et de l'écriture et de education au Brésil, est analysé la section "Littérature enfantine" du Revista de Ensino, éditée de 1902 à 1918, par Association Bienfaisant de l'Enseignant Public Pauliste. A travers l'analyse de la configuration de ces textes, il est vérifié que les traductions/adaptations, paraphrases ou textes originaux d'auteurs brésiliens ou étrangers font partie du corpus précurseur de la littérature enfantine brésilienne et ils ont contribuét à diffuser la conception oscillante entre genre didactique et littéraire lié à la fonction de l'école primaire dans le projet républicain de modernisation sociale et culturelle pour la construction de la nation.

Mots-clés: littérature enfantine, Revista de Ensino, histoire de la littérature enfantine, histoire de l'enseignement de la lecture et de l'écriture, histoire de l'éducation au Brésil. 


\section{Introdução}

C om a proclamação da República brasileira, em 1889, iniciou-se processo de organização de sistema de instrução pública incialmente conduzido pelos governos estaduais, a fim de concretizar as aspirações do projeto republicano de nação. Especialmente durante a Primeira República (1899-1930), a preocupação com a formação de professores, a expansão da rede de escolas primárias e as contribuições da pedagogia e da psicologia para a concepção de infância, dentre outras inovações, demandaram modernização e padronização de métodos de ensino, em particular, os relacionados com leitura e escrita. Assim, foram também necessários textos (especialmente escritos por brasileiros, sobre temas brasileiros, em lugar das adaptações e traduções de livros para crianças e de clássicos estrangeiros para adultos) para serem lidos pelas crianças brasileiras na escola primária, a fim de Ihes oferecer modelos de leitura e escrita assim como comportamentos de civilidade e moralidade, alinhados com os ideais republicanos e o projeto de construção da nação desejada.

Textos escritos especificamente, ou não, para utilização por alunos na escola primária caracterizaram um dos aspectos privilegiados da nova concepção de educação, para a promoção da identidade e nacional em consonância com as urgências políticas, sociais e educacionais daquele momento. Essa "literatura escolar" (ARROYO, 1968) desempenhou importante função no processo histórico de constituição de modelos de educação escolar, de ensino de leitura e escrita e de constituição da literatura brasileira "propriamente dita".

Para esse fim, até o final do século XIX havia poucos livros (de caráter instrucional ou não), livros didáticos e "jornais educativos e de ilustração". Nesses "suportes", eram publicados textos traduzidos/adaptados ${ }^{2}$ ou escritos por portugueses ou brasileiros, além daqueles livros publicados na extensão e no idioma originais (Francês, Espanhol, Italiano, Inglês). Essa "literatura escolar" era então caracterizada como "[...] uma curiosa mistura de obras de caráter escolar e puramente de ficção, algumas mesmo de autores clássicos." (ARROYO, 1968, p. 19) e corresponde, como corpus precursor, a um dos "estágios do processo evolutivo" da literatura infantil brasileira, que "aparece" como tal — ou seja, "como gênero pleno e definido" (ARROYO, 1968) a partir da publicação do livro Narizinho arrebitado (1921), de José Bento Monteiro Lobato, cuja obra literária para crianças incorporou a qualidade (estética) ausente na "literatura escolar" com fins meramente didático-pedagógicos. ${ }^{3}$

\footnotetext{
2 Esse termo é utilizado aqui para designar versões abreviadas de textos ou diversas formas de adaptação, tais como, substituição de palavras ou mera exclusão de trechos.

${ }^{3}$ Essa interpretação da obra de Lobato como "ato fundador" da literatura infantil brasileira se sedimentou especialmente a partir da década de 1980, com a publicação do já clássico livro das pesquisadoras Marisa Lajolo e Regina Zilberman (1984), cujo ponto de vista está centrado na teoria e história literária. Esse livro, por sua vez, estabeleceu-se como "ato fundador" do campo de estudos e pesquisas sobre literatura infantil (e também juvenil, mais recentemente), exercendo, até os dias atuais, decisiva influência na produção acadêmico-científica sobre o tema. Nos últimos anos, porém, alguns pesquisadores do campo da história da educação vêm questionando a interpretação dessas pesquisadoras a respeito do lugar de Lobato como fundador do gênero e vêm defendendo ponto de vista segundo o qual esse lugar cabe ao professor e escritor Thales de Andrade, pela publicação do livro Saudade, em 1919. No entanto, além da preeminência cronológica da obra deste escritor, do ponto de vista da história da educação não se têm questionado outros aspectos determinantes da interpretação de Arroyo, Lajolo e Zilberman, como a qualidade estética da obra de Lobato. Trata-se, assim, não propriamente de disputas de interpretação conforme mesmos critérios, mas de proposição de novo olhar, a partir das características assumidas no movimento histórico de constituição
} 
Assim, no estudo da história da literatura infantil brasileira deve ser considerada sua estreita relação com a história da educação brasileira. ${ }^{4} \mathrm{De}$ fato, nas duas últimas décadas, no campo da história da educação brasileira ${ }^{5}$, ampliaram-se estudos sobre diferentes aspectos da história da leitura e seu ensino escolar assim como da literatura infantil em suas relações com a escola. ${ }^{6}$ Nesses estudos, tem-se utilizado, de forma direta ou indireta, o já clássico livro de Arroyo, e a atenção de pesquisadores tem se voltado, por vezes de forma reiterativa, para os textos ainda localizáveis, dentre os do extenso e denso corpus inventariado pelo historiador, conforme seus critérios e possibilidades de pesquisa. ${ }^{7}$

No entanto, no corpus documental reunido por Arroyo não estão incluídos, por exemplo, muitos textos "avulsos", especialmente aqueles publicados na Seção "Literatura infantil" (ou títulos similares, ou mesmo sem título) da Revista de Ensino, editada entre 1902 e 1918, pela Associação Beneficente do Professorado Público Paulista, criada em 1901. E, embora nas últimas décadas diferentes aspectos desse periódico educacional tenham sido explorados por pesquisadores brasileiros, os textos da Seção mencionada permaneceram inexplorados ${ }^{8}$ talvez por serem menos visíveis, considerando sua forma de circulação. Mas seu estudo pode contribuir para compreender importantes aspectos das histórias da literatura infantil, do ensino de leitura e escrita e da educação no Brasil.

O objetivo deste artigo é analisar os principais aspectos constitutivos da configuração ${ }^{9}$ dos textos publicados nessa Seção. A análise se baseia na hipótese que, com essa Seção, a Revista de Ensino contribuiu para disseminar e consolidar no Brasil a concepção de literatura infantil como gênero didático (nele subsumida sua condição de gênero literário), e ramo da Pedagogia (nele subsumido seu pertencimento ao ramo das Letras).

Por meio de seleção, tradução/adaptação, elaboração original ou paráfrase de textos publicados na Seção, os editores da Revista foram definindo empiricamente um modo de conceber a literatura infantil, do ponto de vista da educação e de suas finalidades escolares, articuladamente ao desenvolvimento da indústria editorial brasileira, alavancada pela publicação de livros escolares e sempre articulada à educação dos cidadãos, função atribuída à escola primária, no projeto republicano de modernização social e cultural necessárias à construção da nação brasileira.

do gênero ao longo do século XX, em que se foi tornando desejável (não mais questionável) sua inserção em e sua vinculação direta com a escola e com o ensino. No atual contexto político e social do Brasil, talvez não faça mais tanto sentido discutir a esteticidade como fator determinante da qualidade do gênero, ou, talvez, do ponto de vista da história da educação não se considere importante levar em conta a característica inexoravelmente interdisciplinar da literatura infantil e a correspondente necessidade de abordagem interdisciplinar do correspondente objeto de estudo. Embora instigantes, questões como essas não cabem nos objetivos nem no espaço deste artigo. Abordá-las-ei em outra oportunidade.

${ }^{4}$ Essa estreita relação pode também ser confirmada por aspectos da trajetória editorial do livro de Arroyo: sua primeira edição, em 1968, foi publicada pela Editora Melhoramentos (SP), na Série "Grandes textos" da prestigiada Coleção "Biblioteca de Educação", organizada e dirigida por Manoel Bergström Lourenço Filho, que é também o autor do prefácio intitulado "Um livro básico sobre literatura infantil brasileira".

5 Também em outros campos da Educação e das Letras, como, respectivamente, Psicologia Educacional e Estudos Literários, vêm se desenvolvendo muitas pesquisas brasileiras sobre literatura infantil.

${ }^{6}$ A esse respeito, ver, por exemplo, Mortatti (2008).

7 De fato, Arroyo adverte sobre as inevitáveis limitações e incompletudes da sua pesquisa pioneira, como consta no subtítulo da primeira edição, de 1968: "ensaio de preliminares para sua história e suas fontes".

8 Coelho (1995) classifica como "período precursor" e "pre-Lobato", na história da literatura infantil brasileira o período entre 1808 e 1919. Ela cita alguns autores que também publicaram textos nessa Seção da Revista, mas não menciona seus textos aí publicados.

${ }^{9}$ Para mais informações sobre o conceito de configuração textual, ver Mortatti (2000, p. 31). 


\section{A Seção de literatura infantil na Revista de Ensino ${ }^{10}$}

A Revista de Ensino teve ampla circulação especialmente entre professores paulistas, com 64 números referentes aos volumes de abril de 1902 a dezembro de $1918 .{ }^{11}$ Em sintonia com o contexto político, social e educacional, o objetivo da Revista era contribuir para a consolidação do sistema público de ensino, por meio do cumprimento de:

[...] uma dupla função com relação ao professorado: a de orientadora (veículo das sugestões pedagógicas e dos métodos de ensino adequados à realidade das escolas públicas) e a de defensora (porta-voz das necessidades e direitos dos docentes). (CATANI, 1989, p. 113).

Dirigida por renomados educadores da época - a maioria deles professores formados pela Escola Normal de São Paulo -, a Revista exerceu sua dupla função por meio de muitas iniciativas, dentre as quais a organização dos professores públicos e a divulgação de programas oficiais de ensino e dos então novos métodos de ensino.

Ao longo dos 16 anos de seu ciclo de vida, com periodicidade bimestral ou trimestral, a Revista passou por três diferentes fases e patrocínios oficiais, ou não. A primeira fase - abril de 1902 a dezembro de 1904 — caracterizou-se pela independência de ponto de vista, ainda que fosse impressa pela Tipografia do "Diario Official" e "sob os auspícios da Directoria Geral da Instrucção Publica do Estado de São Paulo". A segunda fase - fevereiro de 1905 a março de 1910 — caracterizou-se pela ausência de subvenção oficial, tendo sido impressa, a expensas da Associação, por diferentes editoras/tipografias paulistanas. A terceira fase - junho de 1911 a dezembro de 1918 - caracterizou-se pelo retorno da subvenção oficial, com impressão pela tipografia do "Diario Official".

Dentre os editores e colaboradores da Revista, em seus diferentes números e seções, encontram-se professores diplomados pela Escola Normal de São Paulo e pelas escolas normais que foram criadas no interior e no litoral do Estado, desde o final do século XIX, integrando a reforma da instrução pública paulista, iniciada na década de 1890.

Constituindo-se como uma "elite intelectual" (e assim reconhecidos), esses professores tematizavam problemas educacionais relevantes para a época, tais como questões salariais e profissionais do professorado público, bases filosóficas, sociológicas e psicológicas da educação, programas e métodos de ensino das diferentes matérias escolares, especialmente o método analítico para o ensino da leitura. (MORTATTI, 2000).

Muitos deles foram também os tradutores/adaptadores/parafraseadores ou autores ${ }^{12}$ dos textos publicados na Seção em análise e muitos deles mais tarde se profissionalizaram como escritores didáticos, tendo publicado livros para o ensino de diferentes matérias, incluindo cartilhas de alfabetização e livros de leitura, assim como livros de literatura infantil. (MORTATTI, 2000; MORTATTI et al., 2015).

Como anunciada no Editorial do número 1 (Abril de1902), ${ }^{13}$ "Litteratura Infantil" era

\footnotetext{
10 Neste tópico, são apresentadas breves informações sobre a Revista, selecionadas dentre o conjunto consistente de estudos que vêm sendo divulgados nas últimas décadas, sobretudo a partir do estudo pioneiro de Catani (1989).

11 O volume correspondente ao quarto número (de junho a dezembro) foi publicado no ano seguinte.

12 Sobre a autoria dos textos, ver esclarecimentos no tópico 2 deste texto.

${ }^{13}$ A equipe editorial era composta por: Editor-Chefe: A. de O. Barreto; Editor-Secretário: R. Puiggari; Editoresefetivos: L. J. de Brito, J. P. e Silva, J. L. Rodrigues, A. B. da Silveira, E. M. Arantes, R. R. Dordal, J. C. B. dos Reis Junior.
} 
a terceira dentre as oito seções da Revista:

1 - Questões gerais, comprehendendo o desenvolvimento de theses sobre assumptos pedagogicos, que a Associação fornecer;

II - Pedagogia prática;

III - Litteratura Infantil. - Contos infantis e selecção de poesias, diálogos e pequenas comedias para recitação;

IV - Critica sobre trabalhos escolares;

$\mathrm{V}$ - Hymnos escolares;

$\mathrm{VI}$ - Movimento associativo;

VII - Actos officiaes;

VIII - Noticias e annuncios. (REVISTA DE ENSINO, 1902, p. 4). ${ }^{14}$

Com variações e de forma explícita, ou não, essa Seção se manteve em 62 dos 64 números publicados durante o ciclo de vida da Revista. A Seção foi sofrendo modificações em seus títulos (não somente de ordem ortográfica) ${ }^{15}$, número de ocorrência e número de páginas, como se pode observar no Quadro 01. Os conteúdos são, porém, similares, aspecto que permite considerar que se trata da Seção em análise, mesmo quando os títulos não remetem diretamente à proposta anunciada no número 1 da Revista.

Quadro 01 - Ocorrências de títulos da Seção durante o ciclo de vida da Revista de Ensino.

\begin{tabular}{|c|c|c|c|c|}
\hline TÍTULO DA SEÇÃO & $\begin{array}{l}\text { NÚMERO DE } \\
\text { OCORRÊNCIAS }\end{array}$ & PERÍODO & $\begin{array}{l}\text { NÚMERO MÍNIMO } \\
\text { E/OU MÁXIMO DE } \\
\text { PÁGINAS }\end{array}$ & $\begin{array}{l}\text { FASE DA } \\
\text { REVISTA }\end{array}$ \\
\hline \multirow[t]{4}{*}{ Lit(t)eratura Infantil } & \multirow[t]{4}{*}{26} & Abril/1902 a Dez./1904 & $3 ; 19$ & $1 a$. \\
\hline & & Set./1913 & 5 & 3a. \\
\hline & & Jun./1914 a Dez./1915 & $1 ; 13$ & 3a. \\
\hline & & Mar./1917 & 28 & 3a. \\
\hline \multirow[t]{4}{*}{ Li(t)teratura } & \multirow[t]{4}{*}{23} & Abril/1905 a Mar./1908 & $2 ; 10$ & $2 a$. \\
\hline & & Set./1908 a Dez./1910 & $4 ; 13$ & $2 a$. \\
\hline & & Mar./1913 & 2 & 3a. \\
\hline & & Dez./1917 a Mar./1918 & 30 & 3a. \\
\hline \multirow[t]{5}{*}{ sem título } & \multirow[t]{5}{*}{5} & Fev./1905 & 10 & $2 a$. \\
\hline & & Jun./1908 & 3 & $2 a$. \\
\hline & & Dez./1913 & 30 & 3a. \\
\hline & & Set./1916 & 8 & 3a. \\
\hline & & Jun. e Set./1917 & 48 & $3 a$. \\
\hline \multirow{3}{*}{$\begin{array}{l}\text { Leituras } \\
\text { Supplementares }\end{array}$} & \multirow[t]{3}{*}{4} & Mar./1912 & 9 & 3a. \\
\hline & & Set. e Dez./1912 & 13 & 3a. \\
\hline & & Mar./1914 & 5 & 3a. \\
\hline
\end{tabular}

${ }^{14}$ Será mantida a ortografia original na citação de títulos e trechos dos documentos analisados.

15 Há variações ortográficas na palavra "literatura"/"litteratura", devido à reforma ortográfica no Português escrito, efetuada entre 1904 e 1911 e implementada oficialmente em Portugal. No Brasil, porém, foi implementada lentamente e com idas e vindas, até 1938; depois desse ano, foram efetuadas outras reformas ortográficas da língua portuguesa. 


\begin{tabular}{|l|c|c|c|c|}
\hline TítULO DA SEÇÃO & $\begin{array}{c}\text { NÚMERO DE } \\
\text { OCORRÊNCIAS }\end{array}$ & PERÍODO & $\begin{array}{c}\text { NÚMERO MÍNIMO } \\
\text { E/OU MÁXIMO DE } \\
\text { PÁGINAS }\end{array}$ & $\begin{array}{c}\text { FASE DA } \\
\text { REVISTA }\end{array}$ \\
\hline & & Jun./1912 & 46 & 3 a. \\
\hline Lit(t)eratura Didactica & 1 & Dez./1911 & 10 & 3 a. \\
\hline Diversos & 1 & Jun./1913 & 2 & 3 . \\
\hline Divagações & 1 & Jun./1916 & 5 & 3 3. \\
\hline Variedades & 1 & Dez./1916 & 10 & 3 a. \\
\hline
\end{tabular}

Fonte: Revista de Ensino (1902-1918).

Como também se pode observar no Quadro 01, os títulos mais recorrentes são: "Lit(t)eratura Infantil" (26) e "Li(t)teratura" (23), seguindo-se, em ordem decrescente de ocorrência: seções sem título (5); "Leituras Supplementares" (4); "Lit(t)eratura Didactica", "Divagações" (1), "Diversos" (1) e "Variedades" (1).

É possível notar, ainda, a recorrência de "Literatura infantil" nos anos iniciais e sua predominância nos anos finais da Revista. "Literatura", por sua vez, predomina nos anos intermediários, quando também se observa a presença de outros títulos.

Essa Seção não consta nos números referentes a junho e setembro de 1911 e a março de 1916, coincidindo com o período de transição dos títulos, respectivamente: de "Literatura", para "Litteratura didactica"; e de "Literatura infantil", para "Divagações". E também não aparece nos números referentes a junho a dezembro de 1918. As seções sem título, mas com conteúdos similares, encontram-se nos números publicados em fevereiro de 1905, junho de 1908, dezembro de 1913, setembro de 1916 e junho e setembro de 1917, também coincidindo com transição dos títulos, respectivamente: de "Li(t)teratura infantil", para "Lit(t)eratura"; de "Literatura infantil", para "Leituras supplementares"; de "Divagações", para "Diversos"; e de "Literatura infantil", para "Literatura".

Em geral, a quantidade de páginas ocupadas pela Seção varia entre 2 e 48. No entanto, sua extensão aumenta nos números publicados na terceira fase da Revista, quando há também grande variação de títulos assim como diversidade de conteúdos nos textos.

Considerando apenas as seções (com ou sem título) que foram possíveis de serem identificadas como "Literatura infantil", foram publicados 318 textos. A esse total, podem ser acrescentados aqueles publicados nos números da Revista em que essa Seção não consta explicitamente, mas os textos e sua seleção indicam similaridade com o anunciado nos objetivos da Seção. São eles: a) textos sob o título "Educação cívico-literária" (Vol. IV, n. 5 e n. 6, Março e Maio/1906, p. 816-819; 853-856), escritos por estudantes da Escola Primária anexa à Escola Normal de São Paulo; b) textos dos poetas brasileiros Alberto de Oliveira (1857-1937) e Casimiro de Abreu (1837-1860) assim como do poeta português, Guerra Junqueiro (1950-1923), ${ }^{16}$ dentre outros. Esse conjunto de textos é apresentado como "[...] trabalhos literarios - ineditos uns, já conhecidos outros - que constituem uma colectanea para a Festa das Arvores, a effectuar-se em Setembro" (Vol. X, n. 1, Junho/1911, p. 7-58);

16 Trata-se de reproduções/transcrições de textos publicados em outros veículos e que não foram originalmente escritos para a Revista. 
c) e vários poemas em exaltação à bandeira do Brasil (Vol. X, n. 2, Set./1911).

Cruzando os dados apresentados, são possíveis algumas considerações. A ausência da Seção ou de seus títulos (em momentos de "transição"), a variação dos títulos e o aumento da extensão (ambos ocorrendo predominantemente na terceira fase da Revista) indicam, por um lado, a constante oscilação na classificação dos textos e suas finalidades, relacionadas de certo modo com os objetivos da equipe editorial, assim como com cada fase da revista e suas funções, especialmente a de orientadora dos professores primários por meio de sugestões pedagógicas e métodos de ensino. Por outro lado, o cruzamento desses dados também indica o modo como foram se constituindo nas práticas escolares, no Brasil, o "vínculo de origem" entre literatura infantil e finalidades escolares.

\section{Algumas características dos textos publicados na Seção: autoria, temas, conteúdos e tipos de textos}

Nos textos da Seção, nem sempre é possível determinar a autoria, que, na maior parte das vezes, indica quem os assina, em pelo menos dois tipos de condição, conforme indicada nos textos: autor, propriamente dito, de texto original (ou "inédito"), alguns deles traduções para o Francês (por Hippolyte Pujol) de textos de poetas brasileiros e portugueses; e autor de traduções livres, adaptações, paráfrases ou "imitações".

Como se pode observar no Quadro 02, os que assinam os textos são, predominantemente, professores primários do estado de São Paulo, seguindo-se, em ordem de ocorrência, poetas e escritores brasileiros e estrangeiros, alunos de escolas normais, bibliotecário, filólogo, bacharel.

Quadro 02 - Nome, ocupação principal, número de ocorrências e tipo de texto em relação a autores que aparecem mais de uma vez na Seção.

\begin{tabular}{|c|c|c|}
\hline NOME E OCUPAÇÃO PRINCIPAL & $\begin{array}{l}\text { NÚMERO DE } \\
\text { OCORRÊNCIAS }\end{array}$ & TIPO DE TEXTO \\
\hline Antonio Peixoto - professor & 30 & $\begin{array}{c}\text { Prosa (conto); Poesia; } \\
\text { Comédia infantil; canção; hino }\end{array}$ \\
\hline Francisco F. M. Vianna - professor & 15 & Poesia (inéditas e traduzidas) \\
\hline Romão Puiggari - professor & 13 & $\begin{array}{l}\text { Poesia (2 adaptações, } 2 \text { inéditas); } \\
\text { Prosa (conto) tradução/adaptação } \\
\text { livre/paráfrase }\end{array}$ \\
\hline Pedro de Mello - professor & 11 & Poesia \\
\hline Arnaldo de O. Barreto - professor & 10 & Prosa (5); Poesia (5) \\
\hline Zalina Rolim - professor and escritor & 10 & Poesia (9); conto (trad.) (1) \\
\hline José R. Escobar - professor & 10 & Poesia \\
\hline René Barreto - professor & 9 & Poesia (7); Prosa (1); Hino (1) \\
\hline Carlos A. G. Cardim - professor & 8 & $\begin{array}{l}\text { Comédia (5); Drama (1); Monólogo (1); } \\
\text { Prosa (1) }\end{array}$ \\
\hline Ernestino Lopes - Iybrarian & 7 & Prosa \\
\hline Hyppolyte Pujol* & 7 & Poesia \\
\hline G. Junqueiro - poeta & 5 & Prosa (3); Poesia (2) \\
\hline
\end{tabular}




\begin{tabular}{|c|c|c|}
\hline NOME E OCUPAÇÃO PRINCIPAL & $\begin{array}{l}\text { NÚMERO DE } \\
\text { OCORRÊNCIAS }\end{array}$ & TIPO DE TEXTO \\
\hline $\begin{array}{l}\text { Isabel V. de Serpa - aluno da Escola Normal } \\
\text { de São Paulo }\end{array}$ & 5 & Poesia \\
\hline Octaviano de Mello - professor & 5 & Poesia \\
\hline J. Soares Barbosa - philologist & 5 & Análise de Os Lusíadas \\
\hline Jenny Maia (pseudonym) & 4 & Prosa \\
\hline Luiz de Campos - professor & 4 & Prosa (2); Poesia (2) \\
\hline José B. Coelho - professor & 4 & Poesia \\
\hline Coriolano Martins - professor & 4 & Poesia \\
\hline Theodoro de Moraes - professor & 3 & Prosa \\
\hline Arthur Segurado - professor & 3 & Poesia \\
\hline Dr. José de Freitas* & 3 & Poesia \\
\hline Cortez Franco - professor & 3 & Prosa (2); Poesia (1) \\
\hline Vera Cruz* & 3 & Poesia (2); Hino (1) \\
\hline Oscar Brisolla - professor & 3 & Poesia (3) \\
\hline João Köpke - professor e bacharel & 2 & hino \\
\hline J. Pinto e Silva - professor & 2 & Poesia \\
\hline Carlos Ferreira - professor & 2 & Hino \\
\hline Leon Tolstoi - escritor & 2 & Prosa (trad. R. Puiggari) \\
\hline Damasceno Vieira* & 2 & Poesia \\
\hline Saturnino Barbosa - professor & 2 & Poesia \\
\hline Arlindo Leal - professor & 2 & Vaudeville (2); Alegoria 1) \\
\hline Augusto R. de Carvalho - professor & 2 & Prosa \\
\hline Ricardo Gonçalves - professor & 2 & Poesia \\
\hline Francisco Gaspar - professor & 2 & Poesia \\
\hline Manoel dos Reys - professor & 2 & Poesia \\
\hline Casimiro de Abreu - escritor & 2 & Poesia \\
\hline Alberto de Oliveira - escritor & 2 & Poesia \\
\hline Gustavo Kuhlman - professor & 2 & Poesia \\
\hline Mattos Moreira - professor & 2 & Comédia \\
\hline
\end{tabular}

Fonte: Revista de Ensino (1902-1918).

* Até o momento de finalização deste texto, não foram localizados dados precisos sobre esses autores.

Alguns textos assinados por professores de escolas primárias são de sua autoria, mas há muitas traduções livres, adaptações, paráfrases ou "imitações" de textos de escritores consagrados.

É importante ressaltar que: muitos dos autores brasileiros recorrentes foram formados pela Escola Normal de São Paulo, tendo integrado a "elite intelectual" da instrução pública desse Estado; de alguma forma e em algum período do ciclo de vida da Revista - 
especialmente quando seus textos foram publicados - estavam ligados à Diretoria da Associação Beneficente do Professorado Público Paulista ou à redação da Revista de Ensino; e a maioria deles se repete em números sucessivos, como: Antonio Peixoto, Romão Puiggari, Arnaldo de Oliveira Barreto, José Ribeiro Escobar, Theodoro de Moraes. ${ }^{17}$

Esses professores (e muitos outros) defendiam combativamente o método analítico para o ensino da leitura, pois - parafraseando o eminente educador João Köpke (18571926) — defendiam a "excelência do método analítico" como correspondente à "excelência do regime republicano". E, além de autores de outros textos em vários números da Revista, esses professores elaboraram livros didáticos ${ }^{18}$, como cartilhas de alfabetização e séries de livros de leitura, que foram utilizados por muitas décadas em escolas do estado de São Paulo e de outros estados brasileiros, devido, principalmente, às "missões pedagógicas", por meio das quais alguns desses professores disseminaram as inovações da instrução pública paulista, que eles mesmos contribuíram para formular e implementar nesse Estado.

Nos números iniciais da Revista, predominam textos (originais ou traduzidos/adaptados) assinados por conhecidos professores de São Paulo - capital. Nos números seguintes, foram também publicados muitos textos de professores primários do interior e litoral do Estado, que eram pouco conhecidos, não tendo ocupado posições proeminentes na equipe da Revista ou na administração da instrução pública naquele momento e em décadas posteriores. ${ }^{19}$ Podem, assim, ser considerados "escritores de circunstância", tendo elaborado apenas textos para a Revista, para serem lidos ou recitados em atividades escolares. Certamente, essa situação refletia a política editorial da Revista, que visava à valorização do professor "comum", assim "democratizando" a Associação e possibilitando ampliação de seu círculo de influência.

Quanto ao sexo, os autores são predominantemente homens. Há apenas cinco mulheres ${ }^{20}$, nomeadas a seguir, conforme ordem de ocorrência e número de textos por elas assinados: Zalina Rolim ${ }^{21}(10)$; Isabel Vieira de Serpa ${ }^{22}$ (5); Anna Elisa de Andrada

17 Devido à limitada extensão deste artigo e ao fato de muitos dos professores dessa "elite intelectual" serem bastante conhecidos por pesquisadores brasileiros, não serão apresentados seus dados biográficos. Em relação a alguns deles, muitas informações podem ser localizadas: em pesquisas vinculadas ao GPHEELLB, disponíveis, por exemplo, em <http://www.marilia.unesp.br/gphellb>, em Mortatti; Bertoletti; Oliveira; Mello; Trevisan (2015), onde se encontram estudos sobre autores citados no Quadro 2, como J. Köpke, F. M. F. Vianna, C. A. G. Cardim; e em Mortatti (2018).

${ }^{18}$ Muitos desses livros foram oficialmente aprovados para uso em escolas primárias do Estado de São Paulo e de outros Estados brasileiros.

${ }^{19}$ Não foi possível localizar dados de profissionais de todos os autores, especialmente daqueles que aparecem apenas uma vez na Seção. Mas é importante destacar que muitos deles foram homenageados como patronos de escolas públicas paulistas.

$20 \mathrm{Um}$ dos nomes femininos, Jenny Maia (com quatro textos na Seção), é pseudônimo utilizado por um escritor, que também publicou na Revista (1902) um texto com conteúdo depreciativo sobre o trabalho docente, desqualificando em especial as professoras.

${ }^{21}$ Maria Zalina Rolim Xavier (1867-1961) foi Diretora Assistente do Jardim da Infância anexo à Escola Normal de São Paulo, embora não tivesse o diploma de professora. Além dos textos publicados na Revista de Ensino, é autora de poemas publicados em jornais e revistas paulistas e de dois livros: Coração (1893) e $O$ livro das crianças (1897). Ficou conhecida como uma das primeiras escritoras de literatura infantil brasileira (COELHO, 1995) e foi eleita Patronesse da Cadeira n. 4 da Academia Brasileira de Literatura Infantil e Juvenil fundada em 1961. (OLIVEIRA, 2014).

22 Isabel Vieira de Serpa (e Paiva) (1891-19--) diplomou-se pela Escola Normal de São Paulo. Além de professora primária e de autora de textos publicados na Revista de Ensino (quando era aluna daquela Escola Normal), teve publicados poesia e contos em jornais e revistas e livros para a escola e para a infância, como: Berços e ninhos (1913), Poesias cívicas e escolares (1941), Pingos d'aguas (sem data), Histórias infantis (sem data). (COELHO, 1995). Foi eleita Patronesse da Cadeira n. 17 da Academia Brasileira de Literatura 
Machado (1); Dulce Carneiro Ferreira ${ }^{23}$ (1); e Luisa Nery de Sousa (1). ${ }^{24}$

A baixa participação de mulheres como autoras de textos nessa Seção se repete em outras esferas da profissão docente: embora mulheres constituíssem a maioria de estudantes de escolas normais e do magistério público, elas não alcançaram a direção da Associação Beneficente do Professorado Público Paulista e, assim, também não participaram da produção do "discurso legítimo" para a instrução pública e para a formação e atuação de professores. (CATANI, 1994, p. 137). Deve-se ressaltar, porém, que, comparativamente aos professores (homens) daquelas gerações que participaram ativamente da direção da instrução pública paulista e apesar da baixa participação feminina, Zalina Rolim, Isabel Vieira de Serpa (e Paiva) e Dulce Carneiro se destacaram na vida pública devido a sua obra literária.

Quanto aos escritores de literatura cujos textos foram publicados nessa Seção da Revista, merecem atenção os mencionados a seguir, que são apresentados (nos números de 1903-1904) como de "literatura infantil" (verso e prosa) traduzidos/adaptados, imitados, parafraseados por Romão Puiggari e por ele "colleccionados", sob a classificação "os mestres da literatura infantil", embora nem todos os textos tivessem sido escritos especificamente para crianças. Esses escritores são os seguintes: François Fénelon, Hans Christian Andersen, Jean Pierre de Florian, José Selgas, Thomaz Iriarte, José de Alencar. Além desses, são apresentados na Seção, textos de outros escritores: Léon Tolstoi (apresentado como "escritor didático"), Hippolyte Pujol (que traduziu para o Francês poemas de Valentin Magalhães), Julio Diniz, Guerra Junqueiro, Filinto de Almeida, Casimiro de Abreu, José de Alencar e Zalina Rolim.

É também importante notar que, nos números de 1905 e 1906, quando o título da Seção passou a ser "Literatura", foram publicadas em sequência análises do clássico poema épico Os Lusíadas, de Luiz Vaz de Camões, elaboradas pelo filólogo português, J. Soares Barbosa. Esse é mais um indicativo da oscilação na definição do que devia ser ensinado como literatura (para crianças) na escola primária.

Quanto os temas e conteúdos, são relativamente diversificados, quando se observa o conjunto de textos publicados durante o ciclo de vida da Revista, particularmente quando eram mais frequentes traduções, adaptações e transcrições de textos em verso e prosa. No entanto, quando se trata de textos de professores e estudantes escritos especialmente para publicação na Revista, verifica-se tendência ao predomínio de temas: de fundo filosófico-moralizante (ex.: amor filial, ao trabalho e à instrução, cultivo das virtudes); de cunho cívico-patriótico e histórico (ex.: amor à pátria e aos símbolos nacionais, datas e heróis nacionais, tributo a professores e escolas, incluindo letras de hinos escolares, criados por professores e alunos); e de cunho protecionista em relação à natureza (ex.: preservação e plantio de árvores, preservação das aves). Estes dois últimos grupos de temas estavam diretamente relacionados com a introdução, em fins da primeira década do século XX, de datas comemorativas no calendário dos grupos escolares.

Como exemplos dos temas mencionados, podem-se destacar os títulos listados a

Infantil e Juvenil. (OLIVEIRA, 2014).

${ }^{23}$ Dulce Carneiro (1870-1942) foi professora primária e poeta, tendo publicado os livros: Folhas, Lições rimadas, e Revoada, todos sem data.

${ }^{24}$ Até o momento de finalização deste texto, não foi possível localizar dados de A. E. de A. Machado e L. N. de Sousa, exceto que a primeira delas foi professora no Jardim da Infância anexo à Escola Normal de São Paulo. 
seguir.

Exaltação da família e do trabalho: "Uma carta de meu pae"; "Uma familia feliz"; "O dedinho vaidoso (sentimentos de união e afeto na família)"; "Saudades de minha mãe;" "Scenas escolares Garrone (Do Cuore - de Amicis)"; "Os trabalhadores", "A fabrica".

Exaltação de virtudes morais: "Sempre a verdade"; "A moedinha"; "O protector"; "As consequencias da vingança"; "O aváro"; "Premio da caridade (inedito)"; "A calumnia (inedita)"; "A virtude de um lacinho de fita"; "Um coração bem formado (inedita)"; "Augusto Comte (Sem sciencia não há salvação) (Do "Poema Transcendente"); "Flôres D’alma Fé; esperança e caridade (Feita com os finaes de uma poesia sobre o mesmo assmpto, n'um torneio poetico - em outubro de 1887)"; "A verdadeira amizade"; "No altar de Fröebel (especial para a "Revista") (quadro allegorico) (escripto por occasião da terrivel secca no Ceará, em 1900)".

Exaltação da escola: "O velho mestre (inedita)"; "Visitando uma escola"; "Hymno official do Grupo Escolar "Dr. Almeida Vergueiro" do Espirito Santo do Pinhal"; "Caminho da escola - À gentil Cici (tematiza a "Cartilha infantil"(?) de Barreto)"; "O bom collegial (inédita) (A meu amiguinho Dagoberto Padua Salles)".

Comemoração de datas cívico-patrióticas e históricas: "Patria"; "Ao Brasil"; "21 de Abril"; "Descobrimento do Brasil (Comedia em um acto)"; "Sete de Setembro (comedia infantil em um acto)"; "Hymno a Patria"; "Hymno da Republica"; "15 de Novembro (comedia infantil em um acto); "Um quadro da escravidão (Drama infantil em um acto)"; "Episodio da Guerra do Paraguay (para reproducção em classe)"; "Saudação a Bandeira"; "A descoberta da America"; "O pequeno patriota (Para Léo Bellegarde)"; "A guerra".

Exaltação e defesa da natureza: "O poema da laranjeira (inedito)"; "Duas amoras (inedito)"; "Ninhos (inedita)"; "Historia de um grillo"; "Rio Amazonas"; "Hymno das arvores"; "Meu passarinho (Para a Festa das aves)"; "Utilidade das plantas - Para a Festa das arvores)"; "A figueira (Para a Festa da Arvore)"; "As flores (Para a festa das arvores)"; "Um sabiá prisioneiro"; "A liberdade das aves (dialogo) (Para a 'Revista de Ensino')".

Quanto à forma, predominam textos em verso (certamente por causa da brevidade de sua extensão, apropriada para ser publicada no espaço da Seção e para ser lida por crianças), dentre os quais se incluem sonetos, orações fúnebres, poemas líricos ou épicos de formas livre ou fixa. Seguem-se, de acordo com o número de ocorrências: textos em prosa (contos, fábulas, "casos", alegorias, dissertações); letras de hinos cívicos e escolares; pequenas peças de teatro (comédias e dramas); discursos; e análise de Os Lusíadas, de Camões.

Como indica o conjunto de características apresentadas, um importante aspecto comum a todos os textos da Seção é seu endereçamento explícito (não na origem, mas em sua na seleção, ordenação e função) a professores, intermediariamente, e aos alunos, privilegiadamente. Quanto ao endereçamento aos professores (de acordo com a função orientadora da Revista), certamente era preciso oferecer a eles modelos de ensino, em momento em que era ainda incipiente no Brasil a produção editorial de livros didáticos e material impresso adequados às necessidades da nascente escola pública brasileira. Ao mesmo tempo, enfatizava-se a necessidade da leitura "com sentido" e de escolarização do maior número possível de crianças brasileiras ou filhas de imigrantes. $E$, em decorrência do gradativo aumento da preocupação com a infância e suas peculiaridades, 0 endereçamento direto aos alunos pode ser entendido como empenho de lhes oferecer 
modelos de comportamentos e sentimentos, comprometidos com a formação moral, intelectual, afetiva e cívico-patriótica dos futuros cidadãos que a escola republicana tinha por objetivo formar.

\title{
A síntese por Antonio de Sampaio Doria: literatura didática.
}

Como mencionado, a Seção não aparece no volume XVIII, que contém os números 1 a 4, referentes ao período de junho a dezembro de 1918. Esse volume - com que se encerrou o ciclo de vida da Revista - foi publicado depois de seu "desapparecimento momentaneo", desde março de 1917. Como esclarecem seus redatores no Editorial do volume de 1918, o objetivo da "nova fase" da Revista que se pretendia iniciar era, não transformá-la completamente, mas tentar satisfazer, com "outra feição mais pratica e útil”, as "novas e prementes necessidades" criadas pelo desenvolvimento das escolas primárias, considerando especialmente as dificuldades dos professores iniciantes e veteranos. Ao mesmo tempo, sem "desprezar o passado", nem a variedade de opiniões, mas preocupados com as "innovações perigosas", os editores assim apresentam a função da Revista:

[é] preciso, pois, que a Revista, como único órgão do ensino no Estado, zele cuidadosamente do patrimônio existente e aproveitável, e indique, mais cuidadosamente ainda, quase as novidades aceitáveis, sem prejuízo do trabalho commum. (REVISTA DE ENSINO, 1918, p. 2)

Apesar (ou por causa?) da ausência da Seção, nesse volume é publicado o artigo "Methodologia do ensino e literatura didactica" (p. 44-75), de Antonio de Sampaio Doria (1883-1964), ${ }^{25}$ um influente político, jurista e educador brasileiro, que se destacou na instrução pública paulista, especialmente no final da década de 1910 e no início da década de 1920, depois de ter liderado a "mais controvertida" reforma educacional paulista sintetizada na Lei n. 1750, de 1920.

\begin{abstract}
Na historiografia educacional brasileira, a figura de Antonio de Sampaio Dória está intimamente associada à talvez mais controvertida reforma do sistema escolar paulista. Implantada no estado de São Paulo, em 1920, a Reforma Sampaio Dória, como ficou conhecida, inverteu a lógica que vinha orientando a institucionalização e a expansão da escola no estado, ao pôr em cena um programa de inclusão escolar das populações então marginalizadas, fundamentalmente comprometido com duas metas principais: a erradicação do analfabetismo e a difusão de um modelo escolar de educação básica capaz de promover a formação do cidadão republicano. Sampaio Dória foi o idealizador e o arquiteto da reforma, mas não o seu executor, já que deixou o cargo de diretor da Instrução Pública Paulista antes mesmo de sua regulamentação. (CARVALHO, 2010, p. 11).
\end{abstract}

Deve-se ressaltar que as ações de Sampaio Dória em defesa da educação popular

\footnotetext{
25 Antonio de Sampaio Doria (1883-1964) diplomou-se Bacharel, em 1908, pela Faculdade de Direito de São Paulo. Em 1914, tornou-se professor de Psicologia Educacional e Educação Cívica na Escola Normal Secundária de São Paulo. Entre 1917 e 1920, integrou o Conselho Deliberativo e a Comissão de Educação Cívica da Liga Nacionalista de São Paulo. Em 1920, assumiu a Diretoria Geral da Instrução Pública do Estado de São Paulo. Em 1922, integrou a comissão de educação da Liga Nacionalista de São Paulo e o grupo de fundadores da Sociedade de Educação de São Paulo. Em 1923, iniciou a publicação de artigos no jornal O Estado de S. Paulo e, em 1926, foi nomeado Professor Catedrático na Faculdade de Direito de São Paulo. Em 1932, foi um dos signatários do Manifesto dos pioneiros da educação nova. Em 1945, foi nomeado juiz do Supremo Tribunal Eleitoral, Ministro da Justiça e Negócios do Interior, na presidência de José Linhares, depois da queda do Estado Novo. (CARVALHO, 2010, p. 143-144).
} 
estavam diretamente relacionadas com sua atuação como militante da Liga Nacionalista de São Paulo26, que:

[...] tomou várias iniciativas de educação popular e teve como plataforma de ação a promoção de campanhas pelo "soerguimento moral da nacionalidade", pelo voto secreto, pelo serviço militar obrigatório, pelo combate ao analfabetismo, pela cultura cívica e pela propagação da instrução. (CARVALHO, 2010, p. 23).

Com sua intensa militância e extensa formação, Sampaio Doria se destacou no cenário reformador do final da década de 1910, tendo participado ativamente da proposição de respostas aos problemas da instrução pública, de que resultou a Reforma de 1920.

Naquele momento, com as profundas mudanças políticas, econômicas e sociais mundiais - especialmente em decorrência da $1^{\text {a }}$. Grande Guerra -, no Brasil também se ampliaram aspirações de desenvolvimento social e econômico para a paz, visando particularmente à modernização e à industrialização de centros urbanos (como São Paulo - capital) e à incorporação do grande número de estrangeiros que imigraram para o país, em busca de melhores condições de vida e trabalho.

Com a finalidade de buscar soluções para os "novos" problemas, muitas foram as iniciativas em nível federal e estadual, em diferentes setores da sociedade. Em relação à instrução pública paulista, foram também decisivas as iniciativas do Dr. Oscar Thompson. ${ }^{27}$ Em 1918, na posição de Diretor Geral da Instrução Pública do Estado de São Paulo, expediu Carta Circular e o relatório contido no Annuario de Ensino desse mesmo ano. No relatório, formula problemas e propostas, solicitando sugestões para resolver os problemas do analfabetismo. Daquela Carta Circular, derivou, dentre outros, a carta aberta de Sampaio Doria (1918a), na qual

[...] são apresentadas as bases de um plano de extinção do analfabetismo, centrado na urgência nacional de "alphabetizar o povo", para "assimilar o estrangeiro" - "A alphabetização do povo é, na paz, a questão nacional por excelencia" - e aspirando a oferecer-lhe "três beneficios minimos": ler, escrever e calcular. (Sampaio Doria, 1918). (apud MORTATTI, 2000, p. 131).

Nesse contexto reformador e em sintonia com outras iniciativas desse educador, foi publicado o artigo "Methodologia do ensino e literatura didactica", na Revista de Ensino (1918/1919). Nele, o educador estabelece as bases para reflexão teórica sobre esse "gênero da literatura" (p. 74), mas o faz no âmbito de argumentação relativa à defesa do método intuitivo para o ensino de todas as matérias escolares, em particular o método

\footnotetext{
${ }^{26}$ A Liga Nacionalista de São Paulo foi fundada em dezembro de 1916, vinculada à secreta Sociedade dos Patriotas da Faculdade de Direito de São Paulo.

27 Oscar Thompson (1872-1935) diplomou-se pela Escola Normal de São Paulo em 1891 e atuou como professor adjunto na Escola Modelo do Carmo (SP-Capital) até 1893, quando assumiu a direção dessa escola, onde permaneceu até 1898 e onde iniciou sua extensa carreira na administração da instrução pública assim como suas atividades como implementador da reforma da instrução pública paulista, iniciada em 1890. Dentre as várias posições que ocupou, destacam-se: Diretor da Escola Normal de São Paulo (1901-1920, com interrupções); Diretor Geral da Instrução Pública paulista (1909-1910/1917-1920); propositor e defensor do método analítico para o ensino da leitura, de cartilhas e livros de leitura e experiências em psicologia científica e bibliotecas escolares. Destacam-se, ainda: a criação da Diretoria Geral da Instrução Pública (em 1910) e a promoção de iniciativas que inspiraram a reforma da educação realizada por Sampaio Doria, em 1920. Como defensor da "escola moderna", integrou e liderou a "elite intelectual” de sua época, que fundou uma (nova) tradição no ensino de leitura e escrita. (MORTATTI, 2000).
} 
analítico para o ensino da leitura.

De acordo com Sampaio Doria (1918b), acompanhando a marcha mental e a atividade pessoal do educando, na marcha intuitiva há "[...] dois objectos dignos de estudo: são estes todos, que iniciam os conhecimentos, e estas analyses, que os aperfeiçôam". ( $p$. 63, grifos no original). Por esse motivo, "[...] quer se trate do ensino primário, quer do superior, o methodo é sempre a intuição-analytica." (p. 68). Esses princípios do método intuitivo-analítico se aplicam também à "literatura didática", cuja importância o autor assim justifica:

[a] linguagem do professor, que fala ou escreve, se confunde com a literatura comum, si não fora a sua preoccupação intuitiva, na escolha dos assumptos, e na maneira de os concatenar e expor. Quem quer que se aventure a escrever para a infância, não logrará uma linha do seu intento, si não pautar toda a sua linguagem pelas indicações da intuição analytica no seu espírito, no seu curso, e nos seus fins. (SAMPAIO DORIA, 1918b, p. 68)

Enfatiza, ainda, a importância das imagens e das ilustrações no livro didático, a fim de garantir a clareza necessária à apresentação de coisas desconhecidas do leitor iniciante.

A literatura didática (ou livros didáticos, ou livros para a infância, ou "linguagem do professor") tem "[...] primeiro, de selecionar, entre os assumptos possíveis, aquelles que mais se adaptem á idade do leitor, a que se destina[m]. Além disto, força lhe é trata-los de modo a manter, contra as indisposições do momento, o agrado e o prazer da leitura". ( $p$. 72), evitando trivialidades que possam enfadar o leitor. Considerando que "[p]or influencia dynamogenica, a emoção agradável da leitura eloquente tonifica o organismo, e concorre prodigiosamente para a saúde e o futuro [...]" (p. 73) e conforme os objetivos da educação, enfatiza:

[a]ttendendo, agora, aos fins da educação, a literatura didactica se há de aprimorar em moralidade, verdade e belleza.

[...]

A literatura didactica não póde allegar a desculpa de que a arte não tem olhos postos na moral, mas na belleza e na graça. Ella é, por destino, moralizadora, e, como se dirige á infancia, o seu rigor, neste particular, tem de ir além do da literatura comum. [...] três qualidades da literatura didactica: "correção moral" sem negativismo; culto fervoroso á verdade; belleza - formação esthética. (p. 74).

$[\ldots]$

Por isso, a literatura didactica, ou linguagem do professor, tem de ser intuitivaanalytica, no seu espírito, na sua marcha e nos seus fins. Intuitiva, no seu espírito, para dar nascimento à clareza; analytica, na sua marcha, para criar e manter o interesse; educativa, nos seus fins, para melhor formação moral, amor à verdadee e affeiçoamento á belleza e á graça. (SAMPAIO DORIA, 1918b, p. 73-75).

É importante ressaltar que, publicado no último volume da Revista - que já estava consolidada em suas funções de orientação e organização dos professores públicos paulistas - e um ano antes de Sampaio Doria ter proposto a Reforma de 1920, esse artigo não apenas tinha como objetivo encerrar as oscilações em torno do assunto, mas também abrir novas possibilidades "reformadoras" em relação à educação como um todo e à literatura infantil.

Deve-se também recordar que, no âmbito da produção brasileira de literatura infantil, em 1919 foi publicado o livro Saudade, de Thales de Andrade, e, em 1921, o livro Narizinho Arrebitado, de Monteiro Lobato. E, no âmbito da produção sobre literatura infantil, 
importantes tematizações se seguiram à de Sampaio Doria, durante a primeira metade do século XX, em especial: o capítulo do livro Ensinar a ensinar: ensaios de pedagogia aplicados à educação nacional (1923), de Afrânio Peixoto; o artigo "Literatura infantil de uma perspectiva sociológica" (1937), de Fernando de Azevedo; e o artigo "Como aperfeiçoar a literatura infantil (1943), de Lourenço Filho.

De fato, as formulações de Sampaio Doria sintetizavam ideias e práticas usuais até então, consolidando, assim, a íntima e "promíscua" relação entre literatura infantil e literatura didática: aquela é um gênero literário, mas a Beleza (estética) deve estar a serviço do Bem e da Verdade. Apesar das semelhanças, deve-se ressaltar que essa concepção de "literatura didática" não é exatamente a mesma de "literatura escolar" formulada por Leonardo Arroyo (1968). Este historiador enfatiza a escola como lugar de circulação da literatura para crianças; Sampaio Doria, por sua vez, enfatiza o ensino como constitutivo da natureza, destinação e razão de ser da literatura (didática) infantil.

Nesse sentido, o artigo de Sampaio Doria pode ser considerado uma espécie de síntese representativa das discussões realizadas por aquela "elite intelectual", a respeito da definição de literatura infantil e sua função, articuladamente aos objetivos da Revista de Ensino. Em decorrência, pode ser também considerada uma espécie de definição do lugar que a literatura infantil devia ocupar, na República brasileira, na educação de alunos e professores, em especial na escola primária.

Como síntese teórica, o artigo de Sampaio Doria pode, então, ser considerado fundador de polêmicos conceito e funções atribuídas à literatura infantil brasileira, na tentativa de encerrar definitivamente sua "ambiguidade fundante". (MORTATTI, 2008). E, comparativamente aos textos esparsos sobre o assunto - como prefácios e prólogos em livros para crianças - que tinham sido publicados até então (MAGNANI, 1998), o artigo de Sampaio Doria pode também ser considerado fundador de um discurso sobre literatura infantil, no qual se traçaram as bases da constituição de um campo de estudos que se desenvolveu e se consolidou ao longo do século XX, no Brasil. ${ }^{28}$

\section{Considerações finais}

A iniciativa da Revista de Ensino de publicar os textos na Seção analisada contribuiu para contemplar necessidades reiteradamente apontadas por intelectuais daquela época: a produção de livros escritos por brasileiros, com temas brasileiros, para serem lidos na escola brasileira por estudantes brasileiros. É possível, ainda, considerar que as necessidades e finalidades dos textos publicados na Seção estavam, mais imediatamente, relacionadas com as demandas da rotina escolar desejada; e, de modo mais mediato, com a constituição de um tipo específico de aluno-leitor: o futuro cidadão, integrado com as aspirações republicanas para a nação brasileira.

Essa iniciativa contribuiu, sobretudo, para estabelecer certo conceito operante de literatura infantil como literatura para e na escola, por meio de sua definição como gênero didático e ramo da Pedagogia, servindo, assim, às finalidades de um projeto de educação como fenômeno urbano, que demandava a aceleração do processo de aprendizagem

\footnotetext{
${ }^{28}$ Essa concepção de literatura infantil passou a ser programaticamente questionada no Brasil, a partir da década de 1980, quando pesquisadores como Lajolo e Zilberman criticaram a submissão da literatura infantil aos objetivos escolares e defenderam a necessária condição estética desse gênero literário.
} 
daqueles que poderiam constituir um público consumidor desses textos. Por meio dessa iniciativa pioneira, emergiu uma nova produção (institucional) de livros para crianças com novo modo de circulação - que, depois, seria finalmente denominada "literatura infantil" e outro tipo de autor de textos para crianças, que marcaria a formação de leitores, a produção de textos brasileiros desse gênero e os estudos sobre eles.

Desse ponto de vista, a constituição da literatura infantil brasileira está diretamente relacionada, e mesmo condicionada, à educação e à escola, como lugar de formação de leitores e de circulação dos textos, com base em necessidades impostas pelo projeto republicano de nação e seus anseios de modernização, por meio da urbanização e da educação "das massas".

A análise da Seção "Literatura infantil", da Revista de Ensino, propicia, portanto, compreender importante momento do processo de constituição da literatura infantil tanto como gênero literário quanto como objeto de pesquisa ${ }^{29}$, especialmente em relação a aspectos ainda inexplorados da história da educação e do ensino de língua e literatura no Brasil.

Certamente, há muitas possibilidades de desdobramentos da pesquisa sobre o tema deste artigo ${ }^{30}$. No entanto, os aspectos aqui abordados podem contribuir para dar a conhecer um pouco das pesquisas desenvolvidas no Brasil e quão fecundas e promissoras podem ser, especialmente se desenvolvidas com abordagem interdisciplinar e com utilização de fontes primárias que permaneceram por tanto tempo inexploradas e marginais. Sem dúvida, elas podem ser tão loquazes e tão relevantes (como outras fontes mais comumente utilizadas em pesquisas brasileiras sobre o assunto), se o esforço recair sobre as possibilidades de explicação e compreensão, em vez de em julgamentos de valor, com base em sentimentos nostálgicos ou no esquecimento silencioso do passado.

\section{Referências}

ARROYO, Leonardo. Literatura infantil brasileira: ensaio de preliminares para sua história e suas fontes. São Paulo: Melhoramentos, 1968. (2. ed., 1988; 3. ed., Ed. Unesp, 2011).

CATANI, Denice Bárbara. A participação das mulheres no movimento dos professores e a imprensa periódica educacional (1902-1919). Projeto História, São Paulo, n. 11, p. 137, nov. 1994.

Educadores à meia-luz: um estudo sobre a Revista de Ensino da Associação Beneficente do Professorado Público Paulista: 1902-1918. 1989. Tese (Doutorado em Educação) - Faculdade de Educação, Universidade de São Paulo, 1989.

\footnotetext{
${ }^{29}$ Esse é um campo relativamente recente no Brasil, e algumas pesquisas indicam outro aspecto importante: mesmo privilegiando o estatuto literário dos textos de literatura infantil, para seu estudo são necessárias abordagens interdisciplinares, a fim de se considerar e problematizar a polêmica relação entre literatura infantil, ensino de leitura e educação escolar, não como um acidente perturbador a retardar o processo de "maturação" do gênero, mas como condição constitutiva, de que resulta a "[...] unidade múltipla determinantemente constitutiva do gênero - simultaneamente literário e didático —, a qual implica reconhecer que os termos literatura e infantil não se encontram em relação de oposição, mas de complementaridade, embora indiquem hierarquização semântica constitutiva de sua natureza: substantivamente literatura, cujo atributo qualificativo é infantil.”. (MORTATTI, 2001, p. 13-14, grifos no original).

30 Dentre os possíveis desdobramentos, destaco estudos comparativos entre a história da literatura infantil no Brasil e em outros países, especialmente Portugal e países da América Latina.
} 
CARVALHO, Marta Maria Chagas de. Sampaio Doria. Recife: Fundação Joaquim Nabuco, Editora Massangana, 2010. p. 143-144.

COELHO, Nelly Novaes. Dicionário crítico da literatura infantil e juvenil brasileira. 4. ed., São Paulo: Edusp, 1995.

LAJOLO, Marisa; ZILBERMAN, Regina. Literatura infantil brasileira: histórias \& histórias. São Paulo: Ática, 1984.

MAGNANI, Maria do Rosário Mortatti. Entre a literatura e o ensino: um balanço das tematizações brasileiras (e assisenses) sobre literatura infantil e juvenil. Miscelânea, FCL-UNESP-Assis, v. 3, p. 247-257, 1998.

MORTATTI, Maria do Rosário Longo. Ensino de leitura e escrita na escola brasileira: educadores 'intelectuais orgânicos' e disputas seculares por projetos de nação. In: CASTRO, Cesar A.; CASTELLANOS, Samuel L. V. (Orgs.). História da escola: métodos, disciplinas, currículos e espaços de leitura. São Luís: Edufma; Café \& Lápis, 2018. p. 201229.

. Leitura crítica da literatura infantil. Itinerários - Revista de literatura, Araraquara, 17, p. 179-187, 2001.

. Literatura infantil e/ou juvenil: a 'prima pobre' da pesquisa em Letras?. Guavira

Letras, v. 6, p. 43-65, 2008.

Literature for primary school and education of republican citizens, in the 'Revista de Ensino' (São Paulo-BRAZIL) - 1902-1918. History of Education \& Children's Literature (Online), v. X, p. 47-66, 2015. Disponível em: <http://www.hecl.it/>. Acesso em: 17 ago. 2017.

2000.

Os sentidos da alfabetização: São Paulo - 1876/1994. São Paulo: Ed. Unesp,

MORTATTI, Maria do Rosário Longo, BERTOLETTI, Estela N. M.; OLIVEIRA, Fernando R.; MELLO, Márcia C. de O.; TREVISAN, Thabatha A. (Orgs.). Sujeitos da história do ensino de leitura e escrita no Brasil. São Paulo: Ed. Unesp, 2015.

OLIVEIRA, Fernando Rodrigues de. História do ensino da literatura infantil nos cursos de formação de professores primários no estado de São Paulo, Brasil (1947-2003). 2014. Tese (Doutorado em Educação) - Faculdade de Filosofia e Ciências, Universidade Estadual Paulista, Marília, 2014.

REVISTA DE ENSINO, 1902, p. 4.

REVISTA DE ENSINO, ano XVIII, n. 1-4, 1918.

SAMPAIO DORIA, Antonio. Contra o analphabetismo. (Carta Aberta ao Dr. Oscar

Thompson, em reposta ao seu officio sobre como resolver, nas condições actuaes, o problema do analphabetismo. In: Annuario do Ensino do Estado de São Paulo. São Paulo: A. Siqueira \& C., 1918a. p. 58-65.

Methodologia do ensino e literatura didática. Revista de Ensino, São Paulo, v. XVIII, n. 1-4, p. 44-75, jun./dez. 1918b. 
Pesquisa História da educação e do ensino de língua e literatura no Brasil (GPHELLB); presidente emérita da Associação Brasileira de Alfabetização (Abalf).

Endereço: Av. Carlos Artêncio, 356, 17519-255, Marília/SP, Brasil.

E-mail:m.mortatti@unesp.br

Recebido em 18 de agosto de 2017.

Aceito em 22 de junho de 2018. 